\title{
A PESQUISA CRÍTICO-COLABORATIVA E A FORMAÇÃO DAS EDUCADORAS NA CRECHE: ENTRE A CONSTRUÇÃO, A CONTRADIÇÃO E A REFLEXÃ̄'.
}

Núbia Schaper Santos

Não tomo consciência de mim mesmo senão através dos outros.

(Bakhtin)

\section{RESUMO}

Historicamente temos convivido com um dilema desconfortável, com uma divisão antagônica: o saber/pensar - o fazer/agir. Com o descompasso entre o dito e o feito. Esse é em certo sentido um dos dilemas apontados no texto. Assim, este trabalho pretende discutir as contribuições da pesquisa crítico-colaborativa como possibilidade de formação das educadoras na creche. Como pensar uma formação que não desautoriza o outro de suas práticas? Uma formação que não diz que há uma prática mais adequada em detrimento de outras? Como a formação pode ressoar no cotidiano da creche e nas práticas com as crianças pequenas? A pesquisa crítico-colaborativa tem por base $o$ materialismo-histórico-dialético e as ações como práxis. Isso nos leva a crer que a pesquisa é uma atividade coletiva e que os envolvidos no processo são colaboradores e não meramente cooperadores. Há nessa perspectiva o intento de intervir e transformar os contextos no qual se insere. É uma pesquisa produzida com as pessoas e não sobre elas. Neste sentido, a pesquisa crítico-colaborativa propõe a dissolução hierárquica entre os saberes e a diminuição do abismo entre aqueles que pensam e aqueles que fazem.

Escrever é cortar palavras, é aproximar palavras ou até conciliá-las. Aprendi com a filosofia que a escrita deve servir para problematizar a relação que temos com a verdade, e não para transmitir uma verdade. Escrever para que não se faça como se fazia, para transformar a relação que temos com o saber.

Historicamente temos convivido com um dilema desconfortável, com uma divisão antagônica: o saber/pensar - o fazer/agir. Com o descompasso entre o dito e o feito. Esse é em certo sentido um dos dilemas apontados no texto. Assim, este trabalho pretende discutir as contribuições da pesquisa crítico-colaborativa como possibilidade de formação das educadoras na creche. Como pensar uma formação que não desautoriza

\footnotetext{
${ }^{1}$ Texto apresentado no $1^{\circ}$ Seminário de Grupos de Pesquisas sobre Crianças e Infâncias - Grupeci - Juiz de Fora/MG - 2008 .
} 
o outro de suas práticas? Uma formação que não diz que há uma prática mais adequada em detrimento de outras? Como a formação pode ressoar no cotidiano da creche e nas práticas com as crianças pequenas?

A pesquisa crítico-colaborativa tem por base o materialismo-histórico-dialético e as ações como práxis. Isso nos leva a crer que a pesquisa é uma atividade coletiva e que os envolvidos no processo são colaboradores e não meramente cooperadores. Há nessa perspectiva o intento de intervir e transformar os contextos no qual se insere. É uma pesquisa produzida com as pessoas e não sobre elas. Neste sentido, a pesquisa críticocolaborativa propõe a dissolução hierárquica entre os saberes e a diminuição do abismo entre aqueles que pensam e aqueles que fazem.

Entendemos que a formação das educadoras deve contemplar não somente os saberes produzidos e sistematizados pela academia, mas também o permanente diálogo com outros espaços, entre eles, o contexto da própria creche. Portanto, essa formação deve partir dos conflitos, das interrogações, das tensões, dos questionamentos que emergem cotidianamente e que podem ser a matéria-prima para a reflexão das pessoas envolvidas no processo de construção-descontrução-reconstrução de suas práticas.

A creche, como qualquer outro lugar em que transita o humano, é palco de tradições, contradições e reflexões. Acreditamos na necessidade de aprofundar estudos na área, além de enfrentar os dilemas da formação das educadoras no interior da própria creche.

\section{O que tem da criança na creche?}

Nas últimas décadas temas instigantes têm sido problematizados no interior e exterior da creche, entre eles: a articulação do cuidar-educar; o papel da brincadeira no desenvolvimento infantil; a organização do espaço-tempo; a construção de projetos pedagógicos; a controvertida qualidade na educação infantil; a transferência da administração das creches da secretaria de assistência para a secretaria de educação, entre outros.

Não menos importante, a formação das educadoras figura entre os grandes desafios do cenário educacional brasileiro. Considerando que o tema está no palco há pelo menos 
algumas décadas, discuti-lo no plano teórico é quase um clichê. No entanto, não cessamos de perguntar: como é possível transpor aquilo que acumulamos de conhecimento teórico na academia para o cotidiano e as ações das educadoras no interior da creche?

Antes de apontar os argumentos que podem iluminar a questão anterior, é interessante pensar no espaço da creche, no lugar social que ocupa, que ganha visibilidade e interesse como espaço de investigação na mesma medida em que há o reconhecimento de que a criança é um ser que exercita sua aparência e sua presença no tecido social. Na mesma velocidade em que a infância foi capturada pelos saberes disciplinares (psicologia, pedagogia, biologia, antropologia etc) a partir do início do século XX.

$\mathrm{Na}$ experiência contemporânea observamos uma tendência a dividir o mundo dos adultos e o mundo das crianças. A educação das crianças pequenas acontece não mais vinculada aos espaços comuns dos adultos, mas reservada e substituída pela aprendizagem escolar ${ }^{2}$.

De maneira geral, as creches emergiram na europa, no século XIX, com caráter disciplinador e moralizador. As instituições destinadas a crianças pequenas apresentavam pouca ou nenhuma preocupação com o atendimento das necessidades específicas da criança, pautando-se, em grande parte, por ações repressoras, compensatórias ou de preparação para a escolaridade formal ${ }^{3}$.

Como se contróem esses espaços educacionais e com que finalidade? Parece razoável crer que as creches consolidam-se atendendo às demandas sociais do contexto, configurando-se como espaços diferenciados em vários países do ocidente. No Brasil, essa história acompanha as exigências do processo de urbanização e de industrialização, além de um processo de reorganização da ordem familiar, dado a passagem de um modelo colonial-patriarcal e escravocrata para o surgimento da família nuclear republicana (idem).

\footnotetext{
2 ARIÈS, P. História social da criança e da família. Rio de Janeiro: Zahar, 1978.

${ }^{3}$ BARBOSA, M.C. Por amor e por força: rotinas na Educação Infantil. Porto Alegre: Artmed, 2006
} 
$\mathrm{Na}$ tentativa de conter a mortalidade infantil, consolidar campanhas de amamentação, atender ao contingente de mães solteiras e materializar o discurso moralizador destinado à população de baixa renda, a creche, no Brasil, ainda engendra as características do momento de sua criação.

Se essas instituições foram criadas na perspectiva de contemplar a saída da mulher para o mercado de trabalho, agora a perspectiva é de pensar na criança e na infância que habita a creche. A cultura das crianças e os contextos de onde provêm são temas importantes na empreitada de compreender que o desenvolvimento não pode ser tomado como universal. A criança (ora pura, ingênua, ora programada pela genética ou determinada pelo meio) mostra a marca da sua subjetividade, manifesta condição específica de ler o mundo e inventar formas próprias de apreender a realidade das coisas e da vida.

A idéia da criança como produtora de cultura, como aquela que tem voz não somente para dizer aquilo que queremos ouvir, aparece bastante sólida na academia, ainda que as pesquisas sobre as crianças e suas infâncias seja recente.

Essas suposições sobre a infância como uma experiência da vida e não somente como uma etapa da vida deve-se em parte aos estudos da filosofia, da antropologia e da psicologia. Tomando essa última área como análise, temos que os construtos teóricos desse campo materializou-se gradualmente no interior das práticas e no discurso das instituições. Com o entendimento, a partir principalmente de Vygotsky e Piaget (na idéia da criança que precisa interagir para construir), a criança e a infância tomam visibilidade e tanto os aspectos do desenvolvimento, como o brincar, o brinquedo, espaço onde se brinca, quem brinca ou não brinca passam a ser temas de investigação acadêmica.

A questão que julgo pertinente é por que a infância é ainda capturada como um arranjo para a vida adulta, na conhecida idéia de que uma boa fundação ou um bom alicerce garante a solidez da casa?

Paradoxalmente, a medida em que os estudos caminham para desatar as amarras que historicamente conduziram a idéia de infância como algo palpável, concreto ou que tem 
o caráter de absoluta generalidade, na mesma velocidade tendemos, na relação com as crianças, encarcerá-las simbolicamente ou concretamente nos espaços institucionais construídos para elas. E fazemos isso, com a legitimidade de um discurso normatizador que se estabeleceu como a melhor alternativas para elas.

No Brasil, a Constituição de 1988 e a LDB 9394/96, por exemplo, asseguram que, embora não seja obrigatória, a Educação Infantil é uma modalidade de direito das crianças. A partir desses documentos, a educação da criança de zero a seis anos se torna parte da educação básica, assim como o ensino fundamental e o ensino médio.

Excesso de otimismo seria imaginar que pendências cristalizadas ao longo da história, estariam automaticamente resolvidas com a homologação dessas leis. Há tempos não muito remotos o caráter assistencialista, especialmente da creche, dava e ainda dá a tônica para o atendimento. A idéia de criança aparece associada a uma concepção abstrata e reducionista, privilegiando, dessa forma, "o sujeito escolar" em detrimento do "sujeito criança".

Talvez uma das possibilidades de explicação para este tipo de pensamento esteja na tendência que aparece também no Referencial Curricular para a Educação Infantil (documento importante sob a ótica da conquista da área), em linhas gerais apresenta a Educação Infantil como modalidade de ensino. Corre-se o risco de trazer para a área, a idéia de escolarização do ensino fundamental, representando um retrocesso na discussão de que o trabalho com crianças pequenas deve englobar a educação e o cuidado como binômio indissociável ${ }^{4}$.

Desse percurso até hoje, convivemos ainda com crenças que supõem ser a infância depositária de alguma coisa que irá manifestar-se no futuro. A infância compreendida como uma fase efêmera, passageira e transitória que precisa ser apressada. Arroyo ${ }^{5}$ traduz essa idéia da seguinte maneira:

\footnotetext{
${ }^{4}$ CERISARA, A. B. A produção acadêmica na área de educação infantil a partir da análise de pareceres sobre o Referencial Curricular Nacional de Educação Infantil: primeiras aproximações. In: FARIA, A. L. G.; PALHARES, M. S. (orgs) Educação Infantil pós-LDB: rumos e desafios. Campinas: Autores Associados. São Carlos: Editora UFSCar. Florianópolis: Editora UFSC, 1999.

${ }^{5}$ ARroYO, M. In: VEIGA, C. G.; FARIA, L. M. de. Infância no sótão. Belo Horizonte: Autêntica, 1999. (Prefácio)
} 
o que orienta os projetos pedagógicos é construir na infância o adulto desejado, ordeiro, trabalhador, civilizado, integrado na ordem moderna. A pedagogia termina por não olhar para a infância. As teorias pedagógicas não refletem nem teorizam sobre a especificidade desse ciclo da vida, mas sobre o ciclo da vida adulta. Sobre um protótipo de adulto projetado na infância. (...) No rosto das trinta ou quarenta crianças e adolescentes de cada turma vemos o adulto que a sociedade, o trabalho, o concurso, o vestibular espera. Não vemos nem conseguimos ver a infância, mas o adulto que nela sonhamos.

O que dizer de práticas que tendem a demarcar o mesmo tempo para as crianças realizarem atividades sabemos que elas são diferentes? O que dizer de práticas que insistem em utilizar os momentos de brincar para ensinar? O que dizer de práticas que ensinam as crianças apenas a geometria da vida?

A pergunta que inicia a seção: “o que tem de criança na creche?” presta muito mais a provocação e menos a concepção de que creche, criança e infância são tomados com um sentido singular ou como dado universal. Em que medida pensamos na criança quando organizamos o ambiente, demarcamos o tempo, propomos as atividades?. Talvez devêssemos perguntar também: na companhia de que pressupostos pensamos em tudo isso?

\section{Pelas veredas da formação de educadoras na creche}

Dizer que há atributos, habilidades e competências específicas para trabalhar com crianças pequenas é um tendência recente na história da educação se considerarmos que até bem pouco tempo boa vontade, carinho, paciência, amor eram as características popularmente conhecidas e desejadas. Resumindo: bastava gostar de crianças.

Pensar a formação de educadoras para o contexto da creche é pensar também nos indicadores de qualidade na Educação Infantil. Não por caso, a preocupação com a identidade, a valorização, a história de vida das educadoras têm sido temas estimulantes para pesquisas acadêmicas. 
A legislação aponta conquistas que não se materializaram ainda, trazendo uma equação perversa: quanto menor a idade da criança, menor a oportunidade de formação, e consequentemente, menor a remuneração ${ }^{6}$.

Somente há pouco mais de dez anos, na última LDB, a recomendação de escolarização mínima ficou explicitada (nível médio ou superior e formação em serviço). O embate atual é refletir sobre o desenho da formação. Gradualmente, a educação e cuidado às crianças pequenas, realizado por pessoas que não tinham formação específica ou escolaridade básica, torna-se menos freqüente.

Mas que saberes são eleitos, por exemplo, no nível superior, que possibilitam a construção de práticas que priorizem a criança e sua experiência? Essa interrogação deve ser colocada nas discussões sobre reforma curricular dos cursos que formam o professor na universidade.

$\mathrm{Na}$ Europa, especificamente em Portugal ${ }^{7}$, a universalidade da formação no nível superior é uma realidade desde a década de 80 , destacando-se o processo nocivo da academização na formação do professor. Nocivo porque a universidade prioriza a lógica teórica em detrimento de aspectos afetivos-morais, o que Formosinho nomeia de "a valorização acadêmica distante da prática".

Aqui no Brasil, enfrentamos questões semelhantes no atual momento. Na tradição acadêmica, as disciplinas não comunicam. Muitas vezes, os conteúdos são repetitivos, fragmentados e se afastam do vivido nas instituições que atendem crianças. Em contrapartida, é na universidade o lócus apropriado de produção de conhecimento e, por conseqüência, a possibilidade de formar sujeitos críticos e reflexivos. Então, como equacionar as variáveis desse problema: a dicotomia denunciada entre a abstração dos conceitos e a concretude da vida?

Certa vez uma aluna, em um curso de pedagogia, durante a apresentação de um trabalho, recomendou que ao entrar na sala de atividades de uma escola de educação

\footnotetext{
${ }^{6}$ VASCONCELLOS, V. M.R. Formação dos profissionais de educação infantil. Reflexões sobre uma experiência. Em Aberto, Brasília, Inep, 2001.

${ }^{7}$ FORMOSINHO, J. A universidade e a formação de educadores de infância: potencialidades e dilemas. In: MACHADO, M. L. de. Encontros e desencontros em Educação Infantil. São Paulo: Cortez, 2002
} 
infantil era preciso deixar o adulto do lado de fora. À época, a proposta ressoou exagerada e emocionalmente contaminada. Talvez aquela aluna tivesse razão. Proferimos em nossas práticas de ensino a incongruência dos nossos discursos. Como explicar que é preciso considerar o contexto da criança e a riqueza de suas experiências, se na formação dos educadores, muitas vezes, as práticas das próprias educadoras não são reveladas ou relevantes? Como dizer incessantemente que é necessário diversificar as práticas com as crianças, contemplando os diferentes estilos de aprendizagem para fugir da rotina escravizante se nos cursos de formação as aulas são previsíveis, maçante, em um monólogo sem fim?

O que dizer de um currículo que forma ao mesmo tempo o professor para lidar na educação infantil, nas séries iniciais do ensino fundamental, na educação de jovens e adultos, na gestão? Recentemente o discurso sobre a necessidade de uma pedagogia da infância tem se materializado nas universidades, seminários e congressos da área.

Parece razoável crer que a formação da educadora para o trabalho na creche não se esgota na formação inicial. Esse é apenas um dos lados do problema. Outro concentrase na formação continuada das educadoras. Pautar a formação em questões que partem do cotidiano da creche é um caminho coerente se consideramos que os saberes produzidos na creche pelas educadores são saberes tão importantes quanto aqueles produzidos em outros espaços.

A proposição de que devemos partir das problematizações que emergem do contexto tem sido uma tendência na formação de educadores. Desconsiderar as práticas que constituem o modo de ser e de fazer das educadoras é concordar com o argumento de que o que se faz não tem valor, que é prescindível. Não há prática infalível, exata. O que há é a possibilidade de refletir sobre elas. Refletir diz de retorno. O verbo retornar possibilita fazer a mesma coisa de forma diferente, retornar não é voltar novamente, é voltar diferente.

\section{A pesquisa crítico-colaborativa: construindo possibilidades na creche}

Trabalhar na perspectiva da pesquisa crítico-colaborativa é compactuar com uma determinada visão de mundo. É ter uma crença política, ideológica e ética. É 
compreender o conhecimento em processo, datado no tempo, na história e na cultura. É partilhar conhecimento, é pesquisar com e não pesquisar sobre.

Esse referencial de pesquisa traz a necessidade de colocar em cena o complexo processo de autoconsciência que permite a consciência da ação, para que ao repeti-la, a acão já não seja igual. Para que não se faça como se fazia.

Entende-se que é abstraindo os conceitos cotidianos (individuais e não conscientes) sobre a própria prática de ensino-aprendizagem através de sua relação com a teoria formal (conceitos científicos, ou seja, abstrações hierarquizantes dadas pela cultura), que haverá possibilidade de consciência do próprio fazer pedagógico num sentido mais amplo. Entender estes conceitos científicos possibilita uma revisão da própria ação, seu questionamento e transformação aplicada, uma vez que parte da realidade concreta do sujeito, abstrai teoricamente através da voz de outros e redimensiona internamente para criar externamente . $^{8}$.

A pesquisa crítico-colaborativa propõe uma maneira diferente de olhar o que se olha. Por exemplo, na condição de observador, as questões do campo se apresentam, são selecionadas e analisadas pelo ponto de vista do pesquisador, conforme o objetivo proposto no trabalho. As interpretações sobre a situação investigada são devolvidas (quando são) para o campo dois a quatro anos depois (levando em consideração os programas de mestrado e doutorado). As possibilidades de interpretação, o conhecimento de uma realidade, o aprofundamento de um tema e as inúmeras perguntas suscitas pela pesquisa são importantes para que o conhecimento continue se organizando. Mas, e o campo pesquisado?

O tempo da pesquisa é outro, diferente do tempo da creche (questão da nossa discussão). Olhando o cotidiano de uma creche (de maneira generalizada) percebemos um lugar de acontecimentos. De insistência e resistência, de conformação e divergência, de produção e reprodução, de criação e recriação, de repetição, de experiências. As respostas no cotidiano de uma creche não esperam as respostas construídas pela pesquisa.

\footnotetext{
${ }^{8}$ LIBERALI, F.C. Formação crítica de educadores: questões fundamentais. Taubaté/SP: Cabral Editora e Livraria Universitária, 2008 (p.26)
} 
Em síntese, só faz sentido pensar em uma formação que focalize o trabalho com crianças pequenas, muitas vezes negligenciadas na formação inicial e que parte de questões concretas do cotidiano vivenciado pelas educadoras.

Isso é possível a partir de um conceito central adotado nesse modo de pesquisar: a reflexão crítica. A palavra reflexão aparece no dicionário como sinônimo de retorno do pensamento sobe si mesmo. Sugere transformação da ação e, portanto, transformação social tal como proposta por Paulo Freire. Nesse processo, as práticas emancipatórias se materializam e a consciência crítica da realidade se manifesta. Isso só é possível na interação com o outro. Não é tarefa individual, mas uma prerrogativa que se dá nas relações sociais.

O processo de reflexão, no nível da linguagem, é apreendido a partir de quatro ações que operam concomitantemente, a saber: descrever, informar, confrontar e reconstruir. Em linhas gerais:

Descrever é compreendido como a palavra, a voz do ator sobre sua própria ação, conhecer suas ações; (...) informar envolve uma busca dos princípios que embasam (conscientemente ou não) as ações; (...) o confrontar estaria ligado ao fato de o praticante submeter as teorias formais que embasam suas ações, assim como suas ações, a um questionamento que busca compreender os valores que servem de base para o seu agir e pensar; (...) reconstruir está voltado a uma concepção de emancipação através do entendimento que as práticas acadêmicas não são imutáveis e que o poder de contestação precisa ser exercido .

Não se trata de delegar ao indivíduo a responsabilidade pela mudança social ou o compromisso de sanar as mazelas históricas do processo educacional, que se torna complexo diante das crises sociais e culturais. É fazer com as educadoras compreendam o modo como se constituíram profissionalmente na história, as características do seu trabalho e o modo como trabalham. Compreender a função social da creche, para que serve e para quais interesses atendem. Desvelar o lugar em que estão e por que estão. Pensar o contexto histórico e os mecanismos que regulam as suas práticas, bem como as condições de trabalho. Isso extrapola a reflexão sobre o modo como lida com as

\footnotetext{
${ }^{9} \operatorname{Idem}($ p. 55) 
crianças. A dimensão se amplia do sentido individual de suas práticas para o sentido social de suas práticas.

Contreras revela indagações pertinentes ao que dizemos e recomenda que as façamos aos educadores :

\begin{abstract}
De onde procedem historicamente as idéias que eu incorporo em minha prática de ensino? Como cheguei a apropriar-me delas? Por que ainda continuo respaldando o meu trabalho nelas? A que interesses servem? Que relações de poder estão implicadas? Como estas idéias influem no meu relacionamento com os alunos? À luz do que descobri, como posso trabalhar de forma diferente? ${ }^{10}$
\end{abstract}

As perguntas acima nos dizem: não é saber o que não sabia, mas deixar de saber o que se sabia.

Outra questão colocada na pesquisa crítico-colaborativa é a conjugação do verbo colaborar. Colaborar não é concordar, nem tampouco consentir. Não se interessa pela voz do outro para que ele diga o que se quer ouvir. Colaborar poderia ser sinônimo aqui de questionar, contestar, divergir.

Como qualquer processo de construção, a pesquisa crítico-colaborativa encontra obstáculos tanto na micro-realidade (a creche) quanto na macro-realidade (a secretaria a qual se subordina - assistência ou educação). Na creche, a rotina, a administração, as educadoras, os demais agentes, a comunidade, podem facilitar ou dificultar o processo.

Tomando a situação das educadoras, muitas vezes, há uma expectativa de que elas participarão de mais uma formação em serviço, em que um outro alheio à realidade vivenciada por elas, apontará o que deve ser mudado ou não em suas práticas.

Há uma tendência de querer respostas imediatas para as questões que de fato são urgentes. Há o medo de que as práticas serão julgadas, avaliadas e em última instância, reprovadas. E em função disso, o conservadorismo, a desconfiança e a resistência. Descontruir a imagem do visitante inesperado (a universidade como invasora) e construir um ambiente de colaboração é um desafio cotidiano.

${ }^{10}$ CONTRERAS, J. A autonomia de professores. São Paulo: Cortez, 2002. 
Há ainda a questão do tempo institucional que muitas vezes impede a possibilidade de colaboração na creche. Como conciliar os fazeres pedagógicos cotidianos (que não são poucos) com o tempo para a pesquisa? Isso envolve negociação e concessão. Ficar além do horário de trabalho ou dispensar as crianças para as sessões reflexivas pode ser um ônus elevado para as educadoras e para a comunidade.

Diante das possibilidades e das limitações, típicas de qualquer processo de pesquisa, a proposta da pesquisa crítico-colaborativa auxilia no processo de formação das educadoras na creche porque convoca a universidade a pensar para que serve ou a quem serve a formação oferecida em cursos de formação de professores. Ninguém passa ileso por essa maneira de pesquisar. Nem o campo pesquisado, nem tampouco quem o pesquisa. Presta-se também à revelação dos outros como sujeito protagonistas de um processo histórico. Convidando-nos a ruminar esses temas de outro lugar, com outro olhar, desalojando nossas idéias para pensar outras práticas no interior da própria creche.

\section{Referências}

ARROYO, M. In: VEIGA, C. G.; FARIA, L. M. de. Infância no sótão. Belo Horizonte: Autêntica, 1999. (Prefácio)

ARIÈS, P. História social da criança e da família. Rio de Janeiro: Zahar, 1978.

CERISARA, A. B. A produção acadêmica na área de educação infantil a partir da análise de pareceres sobre o Referencial Curricular Nacional de Educação Infantil: primeiras aproximações. In: FARIA, A. L. G.; PALHARES, M. S. (orgs) Educação 
Infantil pós-LDB: rumos e desafios. Campinas: Autores Associados. São Carlos: Editora UFSCar. Florianópolis: Editora UFSC, 1999.

CONTRERAS, J. A autonomia de professores. São Paulo: Cortez, 2002.

FORMOSINHO, J. A universidade e a formação de educadores de infância: potencialidades e dilemas. In: MACHADO, M. L. de. Encontros e desencontros em Educação Infantil. São Paulo: Cortez, 2002

LIBERALI, F.C. Formação crítica de educadores: questões fundamentais. Taubaté/SP: Cabral Editora e Livraria Universitária, 2008.

VASCONCELLOS, V. M.R. Formação dos profissionais de educação infantil. Reflexões sobre uma experiência. Em Aberto, Brasília, Inep, 2001. 